\title{
Fault Isolation and quality assessment for shipboard monitoring
}

\author{
Lajic, Zoran; Nielsen, Ulrik Dam; Blanke, Mogens
}

Published in:

29th International Conference on Ocean, Offshore and Arctic Engineering (OMAE 2010)

Publication date:

2010

Document Version

Early version, also known as pre-print

Link back to DTU Orbit

Citation (APA):

Lajic, Z., Nielsen, U. D., \& Blanke, M. (2010). Fault Isolation and quality assessment for shipboard monitoring. In 29th International Conference on Ocean, Offshore and Arctic Engineering (OMAE 2010) (29 ed., pp.

OMAE2010-20280). American Society of Mechanical Engineers. http://www.skk.mek.dtu.dk

\section{General rights}

Copyright and moral rights for the publications made accessible in the public portal are retained by the authors and/or other copyright owners and it is a condition of accessing publications that users recognise and abide by the legal requirements associated with these rights.

- Users may download and print one copy of any publication from the public portal for the purpose of private study or research.

- You may not further distribute the material or use it for any profit-making activity or commercial gain

- You may freely distribute the URL identifying the publication in the public portal

If you believe that this document breaches copyright please contact us providing details, and we will remove access to the work immediately and investigate your claim 


\title{
OMAE2010-20280
}

\section{FAULT ISOLATION AND QUALITY ASSESSMENT FOR SHIPBOARD MONITORING}

\author{
Zoran Lajic \\ Technical University of Denmark, \\ Department of Mechanical Engineering, \\ Section of Coastal, Maritime and Structural Eng. \\ Build. 403, 2800-Kgs. Lyngby, Denmark \\ zl@mek.dtu.dk
}

\author{
Ulrik Dam Nielsen \\ Technical University of Denmark, \\ Department of Mechanical Engineering, \\ Section of Coastal, Maritime and Structural Eng. \\ Build. 403, 2800-Kgs. Lyngby, Denmark \\ udn@mek.dtu.dk
}

\author{
Mogens Blanke \\ Technical University of Denmark, \\ Department of Electrical Engineering, \\ Automation and Control Group, \\ Build. 326, 2800-Kgs. Lyngby, Denmark \\ mb@elektro.dtu.dk \\ Norwegian University of Technology and Science, \\ Centre for Ships and Ocean Structures \\ 7491 Trondheim, Norway
}

\begin{abstract}
In this paper a new approach for increasing the overall reliability of a monitoring and decision support system will be explained. The focus is on systems used for ship operator guidance with respect to, say, speed and heading. The basic idea is to convert the given system into a fault tolerant system and to improve multi-sensor data fusion for the particular system. Fault isolation is an important part of the fault tolerant design for in-service monitoring and decision support systems for ships. In the paper, a virtual example of fault isolation will be presented. Several possible faults will be simulated and isolated using residuals and the generalized likelihood ratio (GLR) algorithm. It will be demonstrated that the approach can be used to increase accuracy of sea state estimations employing sensor fusion quality test.
\end{abstract}

\section{INTRODUCTION}

The SeaSense system [1] has been installed on several containerships and navy vessels. The system provides an estimation of the actual sea state, information about the longitudinal hull-girder loading, sea-keeping performance of the ship, and decision support on how to operate the ship within acceptable limits. The system is able to identify critical forthcoming events and to give advice regarding speed and course changes to decrease the wave-induced loads. The SeaSense system is based on the combined use of a mathematical model and measurements from a set of sensors. The sensor system is sketched in Figure 1. Thus, detection of sensor faults is critical for the correct operation of the system. The present paper investigates possibilities to employ fault diagnosis techniques and sensor fusion quality test to improve the dependability of decision support systems such as the SeaSense system. Sensor fault-diagnosis is considered using some of the available measurements: vertical acceleration, heave, pitch and roll.

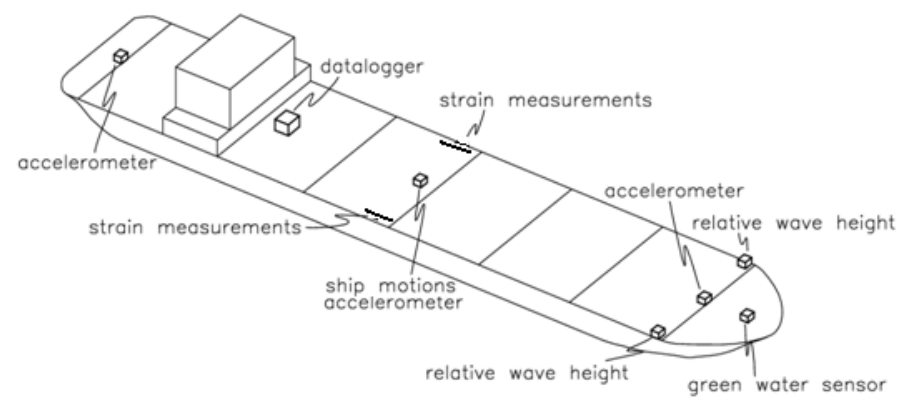

Figure 1. Onboard sensor arrangement 


\section{INCREASING THE OVERALL DEPENDABILITY}

The overall dependability of a shipboard monitoring and decision support system such as the SeaSense system can be improved using the following:

Fault diagnosis - To detect the presence of faults in the system. The faulty signals should be discarded from the procedure for sea state estimation if it is possible, if not the fault should be estimated. In case sea state estimation is conducted by a ship-wave buoy analogy e.g. [2],[3], it is sufficient to use three different ship responses and usually we have more at our disposal.

Sensor fusion quality test - To make a decision on which three ship responses would be the most suitable for wave spectrum estimation. Sensor fusion quality testing (SFQT) should be applied on each combination of three non-faulty signals.

\section{FAULT-TOLERANT APPROACH}

A fault-tolerant monitoring and decision support system has the ability to react on the existence of the fault by adjusting its activities to the faulty behaviour of the system. A fault is something that changes the system behaviour in a manner so that the system does no longer satisfy its purpose. The procedure to make a monitoring and decision support system fault-tolerant consists of two steps [4]:

Fault diagnosis: The existence of faults has to be detected and the faults have to be identified.

Re-design: The system has to be adapted to the faulty situation so that the overall system continues to satisfy its goal.

The fault diagnosis can be divided in three steps on the basis of accuracy, cf. [4]:

Fault detection: Decide whether or not a fault has occurred. This step determines the time at which the system is subjected to some fault.

Fault isolation: Find in which component a fault has occurred. This step determines the location of the fault.

Fault identification and fault estimation: Identify the fault and estimate its magnitude. This step determines kind of fault and its severity.

In the fault diagnosis the sensor measurement $y$ is compared with the analytically computed value $\hat{\boldsymbol{y}}$. The difference between the measurement and the analytically computed value is called a residual.

In the faultless case, the residual is close to zero. It is not exactly zero, due to measurement noise and model uncertainties. In the presence of fault, the residual has some specific, non-vanishing value.

Diagnostic algorithms for continuous-variable systems generally consist of two components:
Residual generation: The model and the input/output pair are used to determine residuals, which describe the degree of consistency between the system and the model behaviour.

Residual evaluation: The residual is evaluated in order to detect, isolate and identify faults.

\section{SHIP MOTIONS IN AN IRREGULAR SEAWAY}

The responses of a ship in an irregular seaway can be deduced by the characteristic wave energy spectrum $S_{\zeta}(\omega)$ and the ship's frequency response functions. In this way, the ship responses can be described by response spectra, where the spectral densities are equal to the product of the spectral density of the waves and the square of the frequency response functions, cf. [5]. Therefore, in the case of long-crested waves, it follows that the response spectra of heave, pitch, roll and vertical accelerations are:

$S_{z}\left(\omega_{e}\right)=\phi_{z}^{2}\left(\omega_{e}\right) S_{\zeta}\left(\omega_{e}\right)$

$S_{\theta}\left(\omega_{e}\right)=\phi_{\theta}^{2}\left(\omega_{e}\right) S_{\zeta}\left(\omega_{e}\right)$

$S_{\varphi}\left(\omega_{e}\right)=\phi_{\varphi}^{2}\left(\omega_{e}\right) S_{\zeta}\left(\omega_{e}\right)$

$S_{z_{m}}\left(\omega_{e}\right)=\phi_{z_{m}}^{2}\left(\omega_{e}\right) S_{\zeta}\left(\omega_{e}\right)$

where:

$S_{z}$ - heave spectrum,

$S_{\theta}$ - pitch spectrum,

$S_{\varphi}-$ roll spectrum,

$S_{z_{m}}$ - vertical acceleration spectrum (midship section),

$\omega_{e}$ - frequency of encounter,

$\phi_{z}$ - response function for heave,

$\phi_{\theta}-$ response function for pitch,

$\phi_{\varphi}-$ response function for roll,

$\phi_{z_{m}}-$ response function for vertical acceleration.

\section{RESIDUALS GENERATION}

For sensor fault detection, it is necessary to find a physical relation between the measured values, i.e. the measured ship responses. Therefore, the wave spectrum in Eqs. $1-4$, can in the individual case be substituted by the response spectra divided with the square of the appropriate frequency response functions found from any of the other expressions:

$$
\begin{aligned}
& S_{z}\left(\omega_{e}\right)-\frac{\phi_{z}^{2}\left(\omega_{e}\right)}{\phi_{\theta}^{2}\left(\omega_{e}\right)} S_{\theta}\left(\omega_{e}\right)=0 \\
& S_{z}\left(\omega_{e}\right)-\frac{\phi_{z}^{2}\left(\omega_{e}\right)}{\phi_{\varphi}^{2}\left(\omega_{e}\right)} S_{\varphi}\left(\omega_{e}\right)=0 \\
& S_{z}\left(\omega_{e}\right)-\frac{\phi_{Z}^{2}\left(\omega_{e}\right)}{\phi_{z_{m}}^{2}\left(\omega_{e}\right)} S_{z_{m}}\left(\omega_{e}\right)=0 \\
& S_{\theta}\left(\omega_{e}\right)-\frac{\phi_{\theta}^{2}\left(\omega_{e}\right)}{\phi_{\varphi}^{2}\left(\omega_{e}\right)} S_{\varphi}\left(\omega_{e}\right)=0
\end{aligned}
$$


$S_{\theta}\left(\omega_{e}\right)-\frac{\phi_{\theta}^{2}\left(\omega_{e}\right)}{\phi_{z_{m}}^{2}\left(\omega_{e}\right)} S_{z_{m}}\left(\omega_{e}\right)=0$

$S_{\varphi}\left(\omega_{e}\right)-\frac{\phi_{\varphi}^{2}\left(\omega_{e}\right)}{\phi_{z_{m}}^{2}\left(\omega_{e}\right)} S_{z_{m}}\left(\omega_{e}\right)=0$

A similar idea of combining measured, calculated and estimated data in shipboard decision support systems has been presented in [6].

Since all the measurements have been taken on the ship, the frequency of encounter should be considered only. As already mentioned, in case sea state estimation is conducted by a shipwave buoy analogy [2],[3], it is sufficient to use three different ship motions (or responses). Therefore, it would be convenient to have expressions that relate three different ship responses, which is readily obtained from Eqs. 5- 10. These residuals are useful not only for fault detection and isolation, but also for the sensor fusion quality testing.

Therefore, every residual is a function of three different ship responses, i.e.:

$$
\begin{aligned}
& R_{1}=f(z, \theta, \varphi) \\
& R_{2}=f\left(\ddot{z_{m}}, z, \theta\right) \\
& R_{3}=f\left(\ddot{z_{m}}, z, \varphi\right) \\
& R_{4}=f\left(\ddot{z_{m}}, \theta, \varphi\right)
\end{aligned}
$$

The system contains four sensors. It is possible to have the following faults:

$f_{l^{-}}$fault on vertical acceleration sensor,

$f_{2}$ - fault on heave sensor,

$f_{3}$ - fault on pitch sensor,

$f_{4}$ - fault on roll sensor.

The fault signatures are shown in Table 1. The symbol $\mathbf{i}$ denotes fault isolation. All four column vectors are different from zero and have a unique signature and therefore all the faults are isolable.

Table 1. Fault signatures.

\begin{tabular}{c|cccc}
\hline$/$ & $f_{1}$ & $f_{2}$ & $f_{3}$ & $f_{4}$ \\
\hline $\mathbf{R}_{1}$ & & $\mathrm{x}$ & $\mathrm{x}$ & $\mathrm{x}$ \\
$\mathbf{R}_{2}$ & $\mathrm{x}$ & $\mathrm{x}$ & $\mathrm{x}$ & \\
$\mathbf{R}_{3}$ & $\mathrm{x}$ & $\mathrm{x}$ & & $\mathrm{x}$ \\
$\mathbf{R}_{4}$ & $\mathrm{x}$ & & $\mathrm{x}$ & $\mathrm{x}$ \\
& $\mathrm{i}$ & $\mathrm{i}$ & $\mathrm{i}$ & $\mathrm{i}$ \\
\hline
\end{tabular}

In decision support systems, it is statistical values which are of concern and therefore it is sufficient to consider the integrated versions of Eqs. 5-10. Integrating over the entire frequency range $\left(\omega_{\mathrm{emin}}, \omega_{\mathrm{emax}}\right)$, leads to the following residuals:

$$
\begin{aligned}
& R_{1}=\frac{1}{\sigma_{z}^{2}} \int\left[2 S_{Z}\left(\omega_{e}\right)-\frac{\phi_{Z}^{2}\left(\omega_{e}\right)}{\phi_{\theta}^{2}\left(\omega_{e}\right)} S_{\theta}\left(\omega_{e}\right)-\frac{\phi_{Z}^{2}\left(\omega_{e}\right)}{\phi_{\varphi}^{2}\left(\omega_{e}\right)} S_{\varphi}\left(\omega_{e}\right)\right] d \omega_{e} \\
& R_{2}=\frac{1}{\sigma_{Z}^{2}} \int\left[2 S_{Z}\left(\omega_{e}\right)-\frac{\phi_{Z}^{2}\left(\omega_{e}\right)}{\phi_{\theta}^{2}\left(\omega_{e}\right)} S_{\theta}\left(\omega_{e}\right)-\frac{\phi_{Z}^{2}\left(\omega_{e}\right)}{\phi_{Z_{m}}^{2}\left(\omega_{e}\right)} S_{Z_{m}}\left(\omega_{e}\right)\right] d \omega_{e} \\
& R_{3}=\frac{1}{\sigma_{Z}^{2}} \int\left[2 S_{Z}\left(\omega_{e}\right)-\frac{\phi_{Z}^{2}\left(\omega_{e}\right)}{\phi_{\varphi}^{2}\left(\omega_{e}\right)} S_{\varphi}\left(\omega_{e}\right)-\frac{\phi_{Z}^{2}\left(\omega_{e}\right)}{\phi_{Z_{m}}^{2}\left(\omega_{e}\right)} S_{Z_{m}}\left(\omega_{e}\right)\right] d \omega_{e} \\
& R_{4}=\frac{1}{\sigma_{\theta}^{2}} \int\left[2 S_{\theta}\left(\omega_{e}\right)-\frac{\phi_{\theta}^{2}\left(\omega_{e}\right)}{\phi_{\varphi}^{2}\left(\omega_{e}\right)} S_{\varphi}\left(\omega_{e}\right)-\frac{\phi_{\theta}^{2}\left(\omega_{e}\right)}{\phi_{Z_{m}}^{2}\left(\omega_{e}\right)} S_{Z_{m}}\left(\omega_{e}\right)\right] d \omega_{e}
\end{aligned}
$$

where:

$\sigma_{z}^{2}$ - heave variance,

$\sigma_{\theta}^{2}$ - pitch variance.

The response spectra can be obtained from sensor measurements by FFT (Fast Fourier Transform).

Several papers deal with fault-tolerant monitoring and/or control of ship responses to the waves. Fault detection and fault-tolerant approaches for the SeaSense system have been presented in [7] and [8] using a different model than the model described in this paper. With the "old" model, purely based on the ship kinematics, it was possible to detect, but not to isolate all the faults. On the other hand, a fault-tolerant sensor-fusion and control system for ship station keeping has been shown in [9], and some applications have been shown for early detection of parametric roll, e.g. [10] and [11].

\section{FREQUENCY RESPONSE FUNCTIONS}

The frequency response functions or transfer functions are very important not only for the fault diagnosis, but also for the estimation of a wave spectrum. The transfer functions can for example be obtained by linear frequency domain strip theory [12], three-dimensional time domain panel codes, or by measurements. In this paper a semi-analytical approach has been used to derive the frequency response functions in terms of closed-form expressions given by [13]. The required input for the procedure is restricted to the main dimensions: length, breadth, draught, block coefficient and water plane area together with speed and heading. The main advantage of the closed-form expression is that they are computationally very efficient, but it is noteworthy that closed-form expressions should be only used in theoretical studies like this; in practical cases state-of-the-art procedures must be applied.

\section{FAULT ISOLATION RESULTS}

As mentioned earlier the response spectra can be obtained from sensor measurements by FFT of the time series at hand. For the simulation of ship motions in waves the method described in [14] has been used. This method has shown good agreement with results from ship trials. The considered ship is a containership (length $\mathrm{L}=275 \mathrm{~m}$, breadth $\mathrm{B}=40 \mathrm{~m}$, draught $\mathrm{T}=$ $12 \mathrm{~m}$ ), which sails at a speed of $10 \mathrm{~m} / \mathrm{s}$ and a mean heading angle of $160 \mathrm{deg}$. Examples of wave elevation and simulated ship responses are shown in Figure 2. 


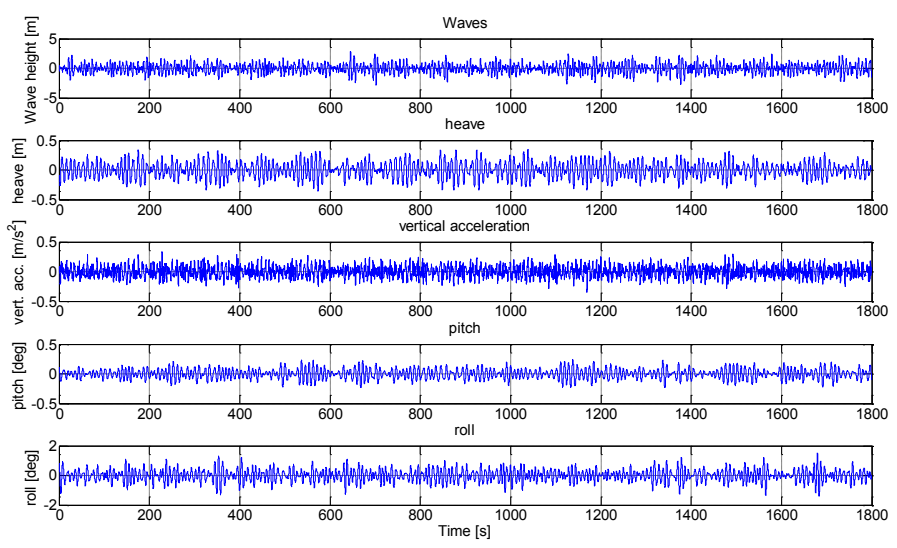

Figure 2. Ship responses on the waves

In case of no faults, residuals $\mathrm{R}_{1}-\mathrm{R}_{4}$ are shown in Figure 3. A window length of six roll periods $(108 \mathrm{sec})$ has been used with overlapping of $90 \%$ between two consecutive windows.
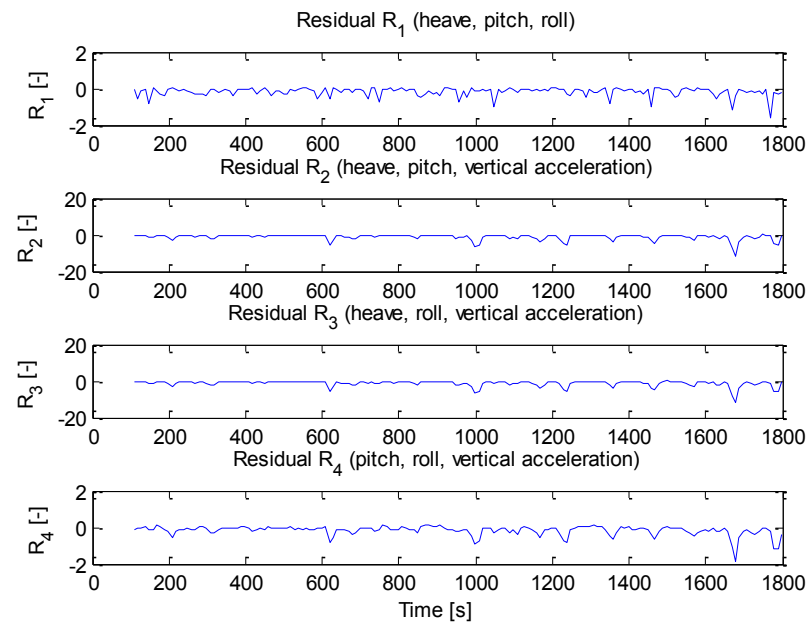

Figure 3. Residuals $R_{1}-R_{4}$ (no faults).

As examples of fault scenarios, faults will be created by adding an extra signal to the sensor output during time interval between $200 \mathrm{~s}$ and $700 \mathrm{~s}$. After $700 \mathrm{~s}$, faults are removed. The faults are simplified as stepwise signals. The scenario is outlined in Table 2, where: $f_{l^{-}}$fault on vertical acceleration sensor, $f_{2^{-}}$fault on heave sensor, $f_{3^{-}}$fault on pitch sensor, $f_{4^{-}}$ fault on roll sensor.

Table 2. Simulated faults.

\begin{tabular}{r|llll}
\hline Fault & Type & Units & Value & Time [s] \\
\hline$f_{I}$ & vertical & $\mathrm{m} / \mathrm{s}^{2}$ & 0.05 & $200-700$ \\
& acceleration & & & \\
$f_{2}$ & heave & $\mathrm{m}$ & 0.5 & $200-700$ \\
$f_{3}$ & pitch & $\mathrm{deg}$ & 0.5 & $200-700$ \\
$f_{4}$ & roll & $\mathrm{deg}$ & 0.5 & $200-700$ \\
\hline
\end{tabular}

\subsection{Change Detection:}

Residuals can be directly evaluated by the GLR (generalized likelihood ratio) test [15]. The GLR test is a useful tool in fault detection. The GLR algorithm relies on the log-likelihood ratio of an observation $z$. Important steps in GLR algorithm are selection of threshold $h$, decision function $g$ calculation and the construction of the alarm diagram using selected threshold and calculated decision function. The GLR decision function can be calculated cf. [4]:

$$
g(k)=\frac{1}{2 \sigma^{2}} \max _{k-M+1 \leq j \leq k} \frac{1}{k-j+1}\left[\sum_{i=j}^{k}\left(z(i)-\mu_{0}\right)\right]^{2}
$$

Where:

$z$ - observation,

$k$ - present time instant,

$j$ - time instant of the fault occurrence (hypothetical),

$M$ - time horizon,

$\sigma$ - variance,

$\mu_{0^{-}}$mean.

The main advantage of the GLR test is that it links the test threshold with the probability of false alarm and the probability of correct detection. Another advantage of this technique is that it can estimate the jump amplitude and the fault appearing time.

\subsection{Results:}

The residuals are evaluated by the scalar GLR test, Eq. 15, using the same horizon $\mathrm{M}=108 \mathrm{~s}$. The alarm diagram is constructed using a decision function and an appropriate threshold.

Residuals in the presence of the fault $f_{l}$ (vertical acceleration) are shown in Figure 4. It is easy to notice the high sensitivity of the residuals to the fault on the vertical accelerometer. The residual $R_{1}$ is unchanged, because it doesn't contain the vertical acceleration.

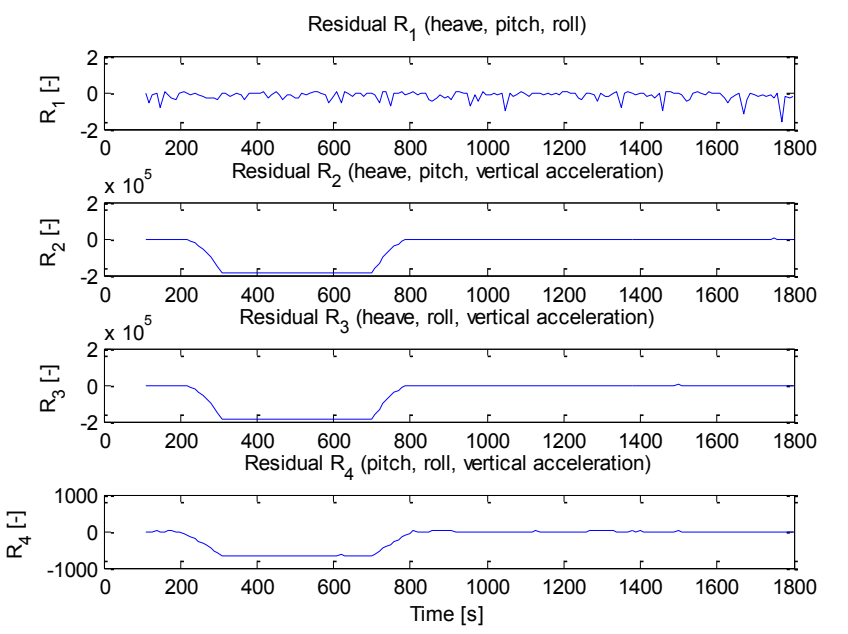

Figure 4. Residuals $R_{1}-R_{4}$, fault $f_{1}=0.05 \mathrm{~m} / \mathrm{s}^{2}$ (vertical acceleration). 
The fault can be detected using GLR test for each residual which contains vertical acceleration $\left(R_{2}, R_{3}\right.$ and $\left.R_{4}\right)$. The results of the GLR test (decision function and alarm) for the residual $\mathrm{R}_{2}$ are shown in Fig. 5. The fault has been detected with a small delay and the system is in an alarm condition in the time interval between approx. 200 seconds and 700 seconds.
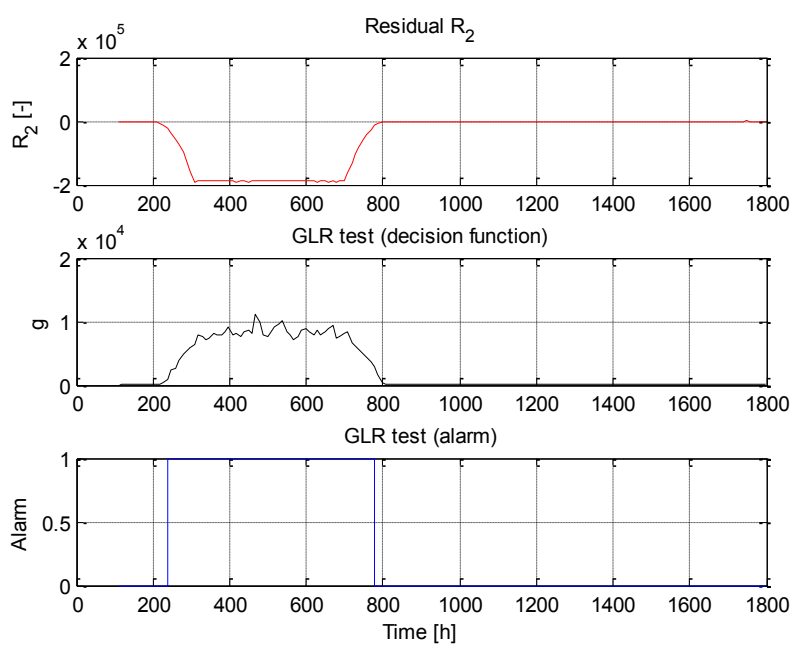

Figure 5. Residual $R_{2}$, fault $f_{1}=0.05 \mathrm{~m} / \mathrm{s}^{2}$ (vertical acceleration) and GLR test (decision function and alarm).

Residuals in the presence of the fault $f_{2}$ (heave) are shown in Figure 6. The fault $f_{2}$ has been detected using GLR test on each residual, which contains the heave motion.
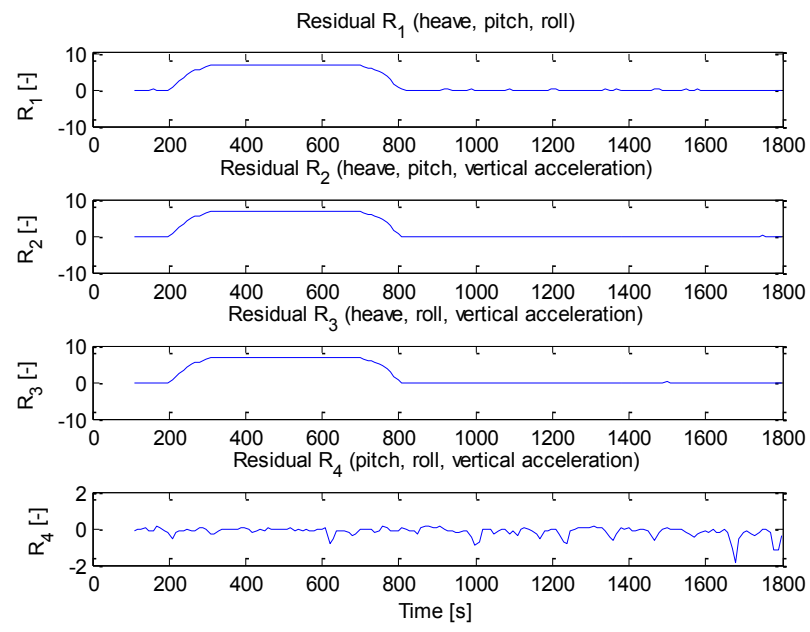

Figure 6. Residuals $R_{1}-R_{4}$, fault $f_{2}=0.5 m$ (heave).

Residuals in the presence of the fault $f_{3}$ (pitch) are shown in Figure 7. The fault $f_{3}$ has been detected on each residual, which contains the pitch motion, using GLR test.

Residuals in the presence of the fault $f_{4}$ (roll) are shown in Figure 8 . The fault can be detected as mentioned earlier using GLR test for each residual which contains roll $\left(\mathrm{R}_{1}, \mathrm{R}_{3}\right.$ and $\left.\mathrm{R}_{4}\right)$.
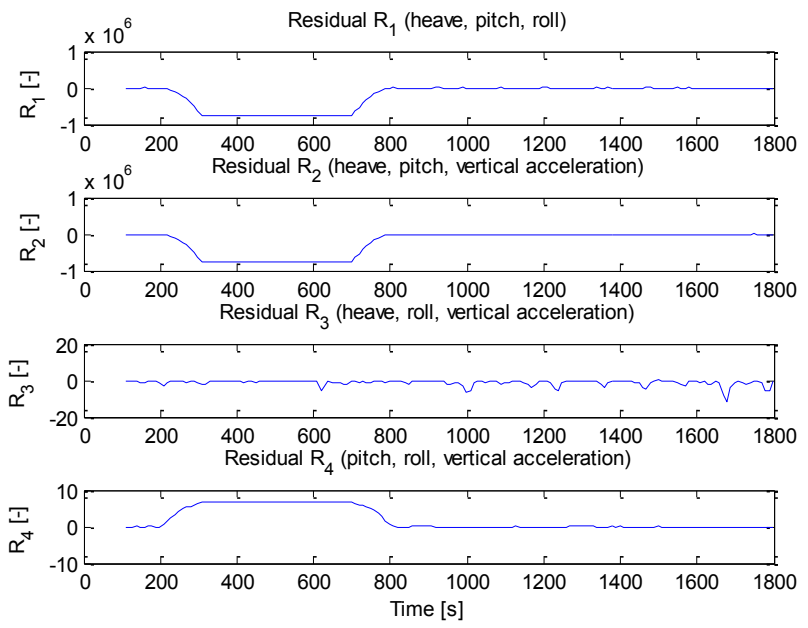

Figure 7. Residuals $R_{1}-R_{4}$, fault $f_{3}=0.5$ deg (pitch).
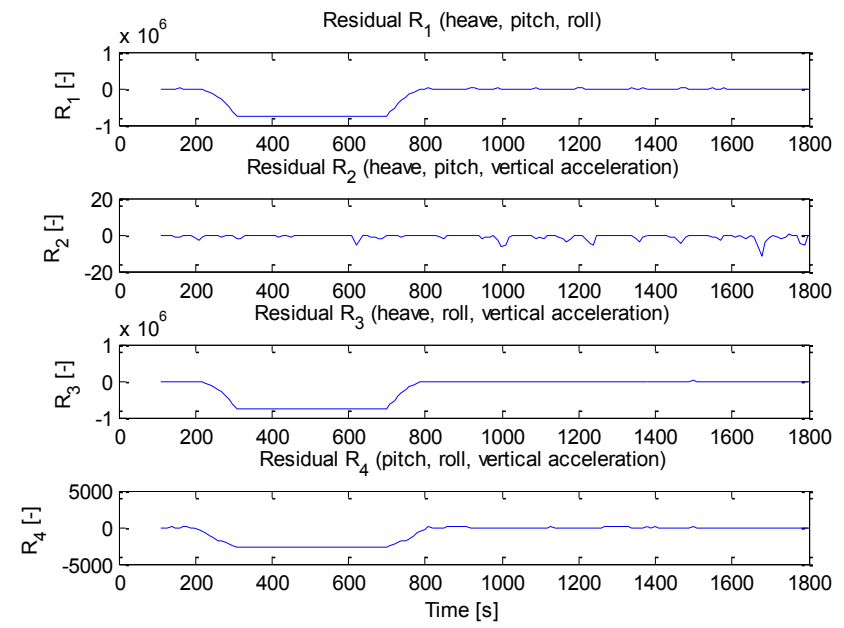

Figure 8. Residuals $R_{1}-R_{4}$, fault $f_{4}=0.5$ deg (roll).

\section{SENSOR FUSION QUALITY TEST}

It is possible analyzing the residuals, to make decision which three signals would be the most suitable for wave spectrum estimation. A fundamental step is to derive residuals which contain three different signals. All the residuals should be first tested using fault- diagnosis and if there is no faults "sensor fusion quality test" (SFQT) should be applied. On the other hand, if there is a fault(s), combinations which contain a faulty signal(s) should be discarded.

The basic idea is to test normality of the residuals and if distributions are similar the best combination will be that with smaller variance. However, if some residual has a perfect normal distribution and other residuals have poor results on the normality test, a residual with normal distribution will be the right choice regardless of the variance. In this paper as normality test will be used Lilliefors test [16]. Lilliefors test is an adaptation of the Kolmogorov-Smirnov test, which is based 
on the maximum difference between an empirical and a hypothetical distribution [17]. Lilliefors test uses the Kolmogorov-Smirnov statistic for testing whether a set of observations is from a normal population when the mean and variance are not specified but must be estimated from the sample. The procedure is: Given a sample of $N$ observation, one determines $D=\max _{X}\left|F^{*}(X)-S_{N}(X)\right|$, where $S_{N}(X)$ is the sample cumulative distribution function and $F^{*}(X)$ is the cumulative normal distribution function with $\mu=\bar{X}$, the sample mean, and $\sigma^{2}=s^{2}$, the sample variance, defined with denominator $n-1$. If the value $D$ exceeds the critical value, one rejects the hypothesis that the observations are from a normal population [16]. Let us consider the residuals shown in Figure 3 again. The results of Lilliefors test and variances are summarized in Table 3.

Table 3. Residuals $R_{1}, R_{3}$ and $R_{4}$ (no faults), variances and the Kolmogorov-Smirnov statistic.

\begin{tabular}{c|cc}
\hline Residual & $D$ & variance \\
\hline$R_{1}$ & 0.01319 & 0.0587 \\
$R_{3}$ & 0.02496 & 2.6950 \\
$R_{4}$ & 0.01340 & 0.0723 \\
\hline
\end{tabular}

From Table 3, one can conclude that the combination expressed by residual $\mathrm{R}_{1}$ (heave, pitch, roll) would be the best choice. It follows $\mathrm{R}_{4}$ (pitch, roll, vertical acceleration) and $\mathrm{R}_{3}$ (heave, roll, vertical acceleration) as a worst solution. Residual $R_{2}$ (heave, pitch, vertical acceleration) has not been considered; because it doesn't contain any asymmetric response with respect to waves entering the starboard/port side. However, it should be pointed out that (heave, pitch, roll) are the best selection only in this simulation and in this time interval. It is not a general solution.

\section{WAVE ESTIMATION}

The sea state estimation is conducted by a ship-wave buoy analogy. In this paper has been applied the Parametric method $[2],[18]$ to estimate the on-site directional wave spectrum. On the assumption that the ship responses are stationary and linear with the incident waves, the complex-valued transfer functions $\phi_{i}\left(\omega_{e}, \beta\right)$ and $\phi_{j}\left(\omega_{e}, \beta\right)$ for the $i$-th and $j$-th responses yield the theoretical relationship between the $i$-th and $j$-th components of the cross spectra $S_{i j}\left(\omega_{e}\right)$ and the directional wave spectrum $E\left(\omega_{e}, \beta\right)$ through the following integral equation [2].

$$
S_{i j}\left(\omega_{e}\right)=\int_{-\pi}^{\pi} \phi_{i}\left(\omega_{e}, \beta\right) \overline{\phi_{j}\left(\omega_{e}, \beta\right)} E\left(\omega_{e}, \beta\right) d \beta
$$

The Parametric method is based on the minimization of the quadratic error of the motions predicted using the estimated spectrum and the measured ones [18]. The wave spectrum, which should be estimated is based on the following $10-$ parameter bimodal spectrum [18],[2]:

$$
\begin{aligned}
& E(\omega, \gamma)= \\
& \frac{1}{4} \sum_{i=1}^{2} \frac{\left(\left(\left(4 \lambda_{i}+1\right) / 4\right) \omega_{p, i}^{4}\right)^{\lambda_{i}}}{\Gamma\left(\lambda_{i}\right)} \frac{H_{s, i}^{2}}{\omega^{4 \lambda_{i}+1}} A\left(s_{i}\right) \times \\
& \cos ^{2 s_{i}}\left(\frac{\gamma-\gamma_{\text {mean }, i}}{2}\right) \exp \left[-\frac{4 \lambda_{i}+1}{4}\left(\frac{\omega_{p, i}}{\omega}\right)^{4}\right]
\end{aligned}
$$

With $H_{s}$ being the significant wave height, $\lambda$ is the shape parameter of the spectrum, $\gamma_{\text {mean }}$ is the mean wave direction, $\omega_{p}$ is the angular peak frequency, and $s$ represents the spreading parameter.

$A(s)=\frac{2^{2 s-1} \Gamma^{2}(s+1)}{\pi \Gamma(2 s+1)}$

is a constant introduced to normalize the area under the $\cos ^{2 s}$ curve and $\Gamma$ denotes the gamma function.

The optimal wave spectrum estimated by the Parametric method is found from the optimization of the parameters:

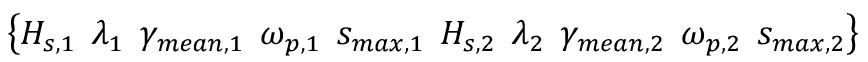

More information about this method can be found in [2],[14],[18].

In the following, the estimated wave spectra using different combinations of ship responses will be presented and discussed. In Figure 9 is shown the true wave spectrum and in Figure 10 estimated wave spectrum using the combination $\mathrm{R}_{1}$ (heave, pitch, roll). In Figures 11 and 12 are shown wave spectra estimated using combinations $\mathrm{R}_{3}$ (heave, roll, vertical acceleration) and $\mathrm{R}_{4}$ (pitch, roll, vertical acceleration), respectively. It is easy to notice that results are in accordance with SFQT. The best results has been obtained using the combination $R_{1}$ and the worst using the combination $R_{3}$ as has been indicated by testing the normality and variances.

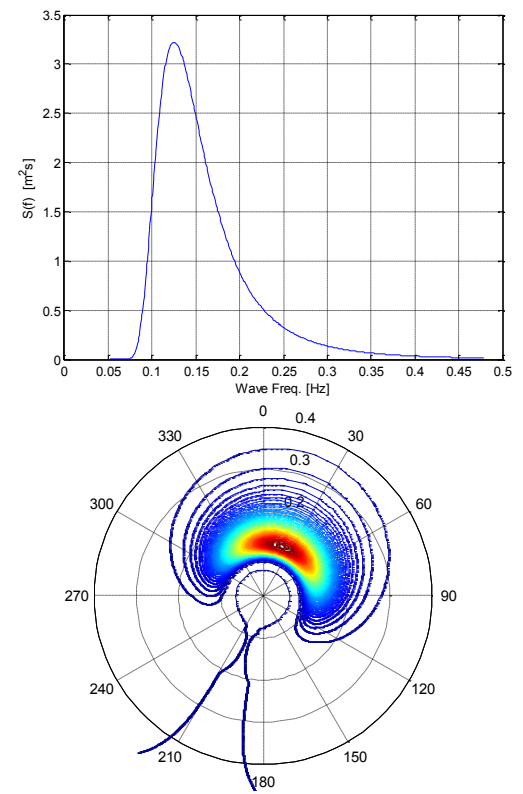

Figure 9. True wave spectrum. 

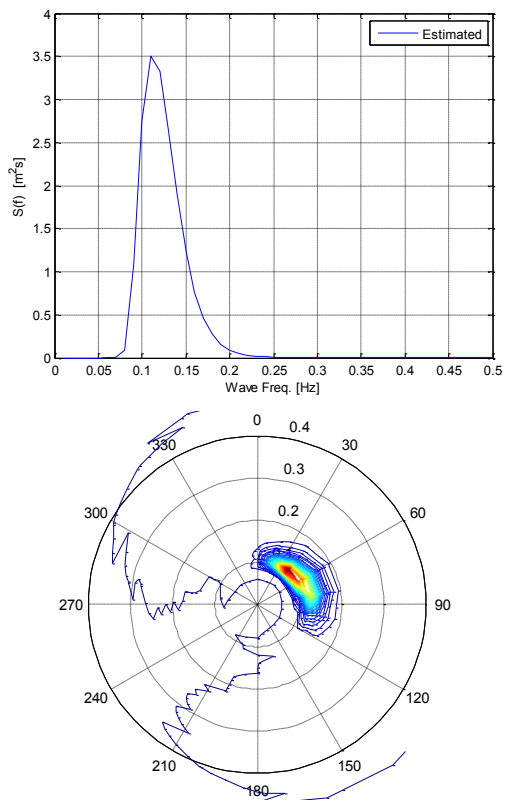

Figure 10. Wave spectrum obtained using the combination $\mathrm{R}_{1}$ (heave, pitch, roll).

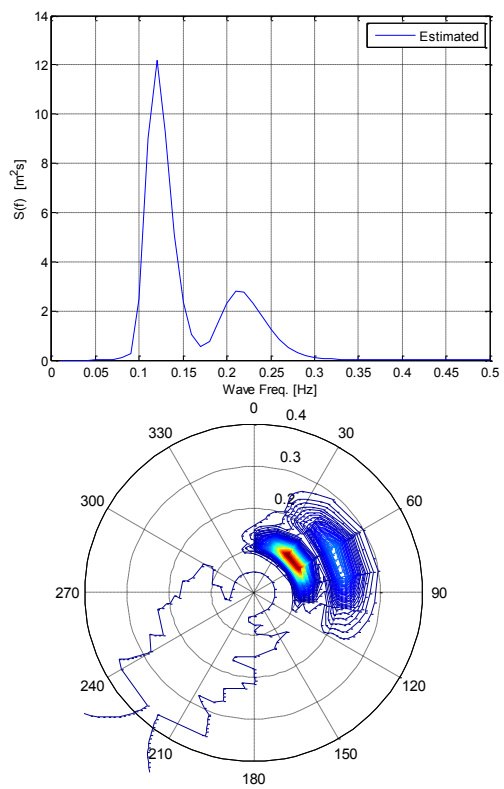

Figure 11. Wave spectrum obtained using the combination $\mathrm{R}_{3}$ (heave, roll, vertical acceleration).
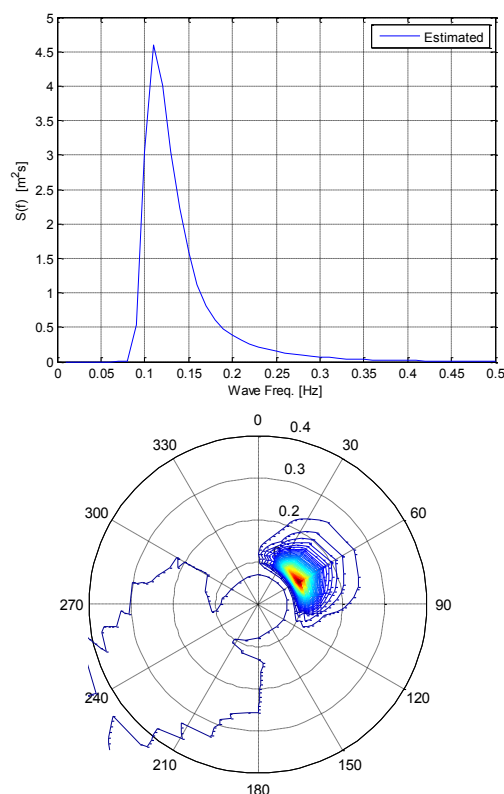

Figure 12. Wave spectrum obtained using the combination $\mathrm{R}_{4}$ (pitch, roll, vertical acceleration).

\section{CONCLUDING REMARKS}

In this paper a new approach for increasing the overall reliability of a monitoring and decision support system has been presented. This approach consists of two elements: fault diagnosis and sensor fusion quality test. The faults were created by adding an extra signal to the sensor's output and the sensitivity of the residuals to the sensor fault was investigated. The residuals were evaluated by the GLR test, and all the faults were detected and isolated. Using the model presented in the paper, we are able not only to detect, as in case of previous models given by [7] and [8], but also to isolate all the faults. Having fault isolation is very important for the design of a fault tolerant monitoring and decision support system. The second part of the paper has been dedicated to improving multi-sensor data fusion and sea state estimation. Therefore, sensor fusion quality test has been suggested as a method for selecting the most suitable set of ship responses for sea state estimation. The certainty of the sensor fusion quality test has been justified.

\section{ACKNOWLEDGMENTS}

The inspiring discussions with Professor Jørgen Juncher Jensen during the writing of this paper are highly appreciated. The present work has been supported by Danish Centre of Maritime Technology (DCMT).

\section{REFERENCES}

[1] Nielsen, J.K ., N.H. Pedersen, J. Michelesen, U.D. Nielsen, J. Baatrup, J.J. Jensen, E.S. Petersen(2006). SeaSense Real-time Onboard Decision Support, Proceedings of WMTC2006, London, UK. 
[2] Nielsen, U.D. (2006). Estimations of on-site directional wave spectra from measured ship responses, Marine Structures, Vol. 19, pp. 33-60.

[3] Nielsen, U.D. (2008), Introducing two hyperparameters in Bayesian estimation of wave spectra, Probabilistic Engineering Mechanics, Vol. 23, pp. 84-94.

[4] Blanke, M., M. Kinnaert, J. Lunze, M. Staroswiecki (2006). Diagnosis and Fault Tolerant Control, Springer Verlag, Berlin Heidelberg.

[5] Bhattacharyya, R (1978). Dynamics of Marine Vechicles. John Wiley \& Sons, New York.

[6] Nielsen, U.D. and J.J: Jensen (2009). A novel approach for navigational guidance of ships using onboard monitoring systems, submitted for possible publication in Reliability Engineering and System Safety.

[7] Lajic, Z., M. Blanke, and U.D. Nielsen (2009). Fault Detection for Shipboard Monitoring - Volterra Kernel and Hammerstein Model Approaches, Procedeengs of 7th IFAC Symposium on Fault Detection, Supervision and Safety of Technical Processes, Barcelona, Spain.

[8] Lajic, Z. and U.D. Nielsen (2009). Fault Detection for Shipboard Monitoring and Decision Support Systems, Proceedings of $O M A E^{\prime} 09$, Honolulu, HI, USA.

[9] Blanke, M. (2005). Diagnosis and fault-tolerant control for ship station keeping, Proc. $13^{\text {th }}$ Mediterranean Conference on Control and Automation, Limassol, Cyprus.

[10] Galeazzi, R., M. Blanke and N. K. Poulsen (2009a). Detection of parametric roll resonance on ships from indication of nonlinear energy flow, Procedeengs of $7 \mathrm{th}$ IFAC Symposium on Fault Detection, Supervision and Safety of Technical Processes, Barcelona, Spain.

[11] Galeazzi, R., M. Blanke and N. K. Poulsen (2009b). Parametric roll resonance detection using phase correlation and log-likelihood testing techniques, Procedeengs of $8 \mathrm{th}$ IFAC International Conference on Manoeuvring and Control of Marine Craft, Guaruja, Brazil.

[12] Salvesen, N., E. Tuck and O. Faltinsen (1970). Ship motions and sea loads, Transaction SNAME, Vol. 78, pp. 250-287.

[13] Jensen, J.J., A.E. Mansour and A.S. Olsen (2004). Estimation of ship motions using closed-form expressions, Ocean Engineering, Vol.31, Issue.1, 61-85.

[14] Nielsen, U.D (2007). Response-based estimation of sea state parameters- influence of filtering, Ocean Engineering, Vol.34, Issue.13, 1797-1810.

[15] Basseville, M. and I. Nikiforov (1993). Detection of Abrupt Changes: Theory and Application. Prentice-Hall.

[16] Lilliefors, H. (1967), On the Kolmogorov-Smirnov test for normality with mean and variance unknown, Journal of the American Statistical Association, Vol. 62. pp. 399-402.

[17] Massey, F.J. (1951), The Kolmogorov-Smirnov Test for Goodness of Fit, Journal of the American Statistical Association, Vol. 46. pp. 68-78.

[18] Tannuri, E., J. Sparano, A. Simos, J.D. Cruz (2003), Estimating directional wave spectrum based on stationary ship motion measurements, Applied Ocean Research, Vol. 25. pp. 243-261. 